\title{
ANALISIS TAMPILAN VISUAL GAME SUPER MARIO BROS DALAM KAJIAN PERSEPSI VISUAL SEBAGAI DASAR PENGEMBANGAN KONSEP VISUAL GAME
}

\author{
Khamadi \\ Program Studi Desain Komunikasi Visual \\ Fakultas IImu Komputer, Universitas Dian Nuswantoro Semarang \\ khamadi.dosen@gmail.com
}

\begin{abstract}
Abstrak
Pada perancangan sebuah game selain memiliki konsep yang berupa gameplay yang kuat dan menarik, harus memperhatikan aspek visual yang diwujudkan dalam desain interface game sebagai media interaksi dengan user. Aspek visual begitu penting untuk menarik minat dari user dan juga untuk memperlihatkan pesan pertama kali kepada user. Dengan visual yang baik, user akan menangkap pesan game dengan mudah dan akan memahami gameplay permainan lebih cepat. Visual yang baik tidak harus dengan gambar yang rumit tetapi bisa dengan gambar yang sederhana yang disusun dengan komposisi yang baik dan desain tata letak yang mudah dipahami oleh user. Dengan menganalisis game Super Mario Bros yang telah terbukti disukai banyak orang meskipun tampilan visual dan gameplaynya sederhana. Maka penelitian ini berusaha mengkaji visual game Super Mario Bros versi 2 Dimensi (2D) dan 3 Dimensi (3D) berdasarkan teori persepsi visual untuk mendapatkan rumusan visual game yang disukai oleh user (pemain game). Kemudian dengan metode komparasi dari kajian tersebut dibuat analisis perancangan tampilan visual game yang baik meliputi aspek gambar/objek, view, komposisi, dan desain tata letak/layout yang berguna sebagai dasar pengembangan visual game selanjutnya.
\end{abstract}

Kata Kunci: Game, Persepsi, Super Mario Bros, Visual

\section{PENDAHULUAN}

Perkembangan teknologi dan informasi telah memberikan dampak positif kepada masyarakat dengan tersedianya berbagai alternatif media dalam penyampaian pesan seperti media surat kabar, televisi, internet, dan smartphone. Pesan yang disampaikan dapat berupa pesan verbal maupun pesan visual. Pesan verbal berupa komunikasi antar individu satu dengan yang lain, sedang pesan visual berupa interaksi antara individu dengan sebuah media visual seperti yang disebutkan di atas.

Kemudian bagaimana dengan game? Bukankah game juga sebuah media visual? Apakah game memiliki peranan dalam penyampaian pesan yang efektif? Game telah dikenal dan terus diminati oleh masyarakat karena menyajikan suatu permainan yang menghibur dan interaktif. Hal ini menjadikan game sebagai media visual yang efektif untuk menyampaikan suatu pesan ke masyarakat. Kemudian efektif di sini berarti user atau pemain game selain mendapatkan hiburan juga secara tidak langsung mendapatkan suatu pesan dari game tersebut. Pesan dapat berupa pesan pengetahuan, pesan sosial, pesan budaya, maupun pesan pengalaman. 
Game merupakan salah satu unsur pengembangan dari desain yang membutuhkan interaksi dari user atau pengguna. Dalam sebuah game terdapat elemen-elemen seperti visual, audio, dan Al (Artificial Intelligence) sehingga pengembangan suatu game, diperlukan integrasi dari bermacam-macam disiplin keilmuan seperti: Game Mechanic, Visual Arts, Programming, Proses Produksi, Audio, dan Narasi, dimana elemen-elemen tersebut membutuhkan pengembangan agar user memiliki fokus dan ketertarikan yang lebih terhadap game yang dimainkan yang berujung pada tercapainya pesan yang ingin disampaikan oleh game tersebut. Tingkat kefokusan dan ketertarikan user dapat dibentuk dengan mengenal user yaitu tentang persepsi user.

Selanjutnya karena fungsinya sebagai media visual, game harus dikembangkan melalui konsep yang teliti dan cermat terutama pada konsep visualnya agar pesan yang disampaikan tercapai, dimana sebuah tampilan visual adalah sensor pertama yang akan diterima oleh indera dalam memainkan sebuah game. Oleh karena itu, sangat penting untuk mengenal user dalam proses pengembangan konsep visual game. Mengenal user dilakukan dengan mengetahui bagaimana user memaknai sebuah tampilan visual atau dikenal dengan persepsi visual. Persepsi visual user dapat dibentuk dengan pengembangan konsep tampilan visual yang dibuat oleh desainer game. Jadi, persepsi user akan dibimbing ke arah yang diinginkan pembuat game sehingga diharapkan user dengan mudah menangkap pesan yang disampaikan.

Game sebagai media interaktif membutuhkan interaksi user untuk memainkannya. Dan dalam interaksi ini muncul komunikasi antara game yang diwakili tampilan visual dengan user sebagai penggunanya. Dalam komunikasi ini, fokus dan ketertarikan user terhadap apa yang diperlihatkan game menjadi elemen penting agar timbul interaksi yang baik. Fokus user ini dibentuk oleh persepsinya terhadap tampilan visual yang ada dalam game. Dengan tampilan visual yang menarik, meliputi elemen visual; desain karakter, objek, bentuk dan warnanya, hingga animasi yang sesuai dengan prinsipprinsip desain dan seni rupa, maka kecenderungan user untuk memberikan perhatian yang lebih dan mulai mengamati secara seksama dan memiliki keinginan untuk memainkan sebagai wujud reaksi atas persepsi visual yang dibuatnya.

\section{TINJAUAN PUSTAKA}

\subsection{Komunikasi Sebagai Proses Penyampaian Pesan}

Dalam interaksi user dengan interface game secara tidak langsung menciptakan komunikasi visual. Komunikasi adalah terjadinya penyampaian informasi dari sumber ke penerima informasi. Dalam komunikasi ada dua komponen utama yaitu komunikator dan komunikan. Dalam menyampaikan informasi perlu adanya media sebagai perangkat untuk menyalurkan informasi. Dan dalam konteks ini, game menjadi media informasi. Dalam interaksi user dengan tampilan visual game, konsepsi komunikasi mengandung pengertian menyampaikan visual, memberitahukan pesan, hiburan, dan maksud pembuat game sehingga game dapat diselesaikan sesuai alur yang telah diberikan sesuai gameplay. 
Menurut Lasswell dalam Mulyana (2005), cara terbaik untuk berkomunikasi ialah dengan adanya interaksi antara Komunikator, Pesan (Message), Media, Komunikan, Efek (Effect, Impact, Influence). Sedangkan dalam game maka unsur-unsur dalam proses komunikasi dapat digambarkan adalah seperti pada gambar di bawah ini;

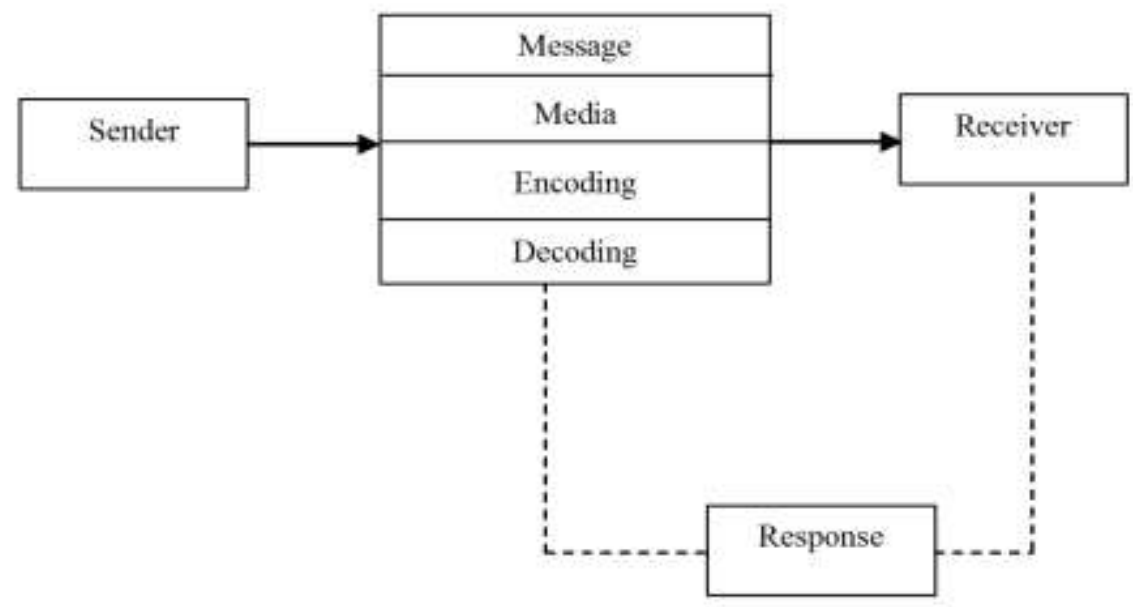

Gambar 1. Model Proses Komunikasi menurut Lasswell dalam Mulyana (2005)

Kemudian dalam user sebagai receiver/penerima pesan menerjemahkan pesan sender/pembuat game akan melalui tahap persepsi yaitu memaknai informasi visual yang ada dalam game.

\subsection{Persepsi Visual Sebagai Proses Penerimaan Pesan}

Menurut Davidof dalam Walgito (2004), persepsi merupakan proses yang digunakan oleh seseorang individu untuk memilih, mengorganisasi dan menginterpretasikan masukan-masukan informasi guna menciptakan gambaran dunia yang memiliki arti. Persepsi tidak hanya bergantung pada rangsangan fisik tetapi juga pada rangsangan yang berhubungan dengan lingkungan sekitar dan keadaan individu bersangkutan.

Mata sebagai indera penglihatan (visual) erat kaitannya dengan pembentukan persepsi manusia. Dengan hanya melihat sesuatu hal maka otak akan merespon dan menterjemahkan dalam bentuk interpretasi. Reaksi otak terhadap apa yang dilihatnya sangat beragam, tergantung pula pada pengalaman hidupnya. Otak mempersepsikan objek visual dengan cara mengorganisasikan komponen-komponen sensasi yang memiliki hubungan, pola, ataupun kemiripan menjadi kesatuan(holistik). Hal seperti itulah yang disebut persepsi visual.

Sarwono (2012) mengemukakan bahwa persepsi visual memiliki beberapa prinsip, yaitu:

a. Wujud dan latar (figure and ground)

Objek yang kita amati di sekitar kita selalu muncul sebagai wujud (figure) sedangkan hal-hal lainya namun tidak menjadi fokus yang diamati disebut latar (ground). Sebagai contoh apabila kita melihat meja di dalam ruangan, maka meja itu adalah 
suatu wujud, sedangkan hal lain seperti lantai, dinding, jendela dan lain sebagainya merupakan suatu latar. Ada kalanya perbedaan antara wujud dan latar tidak begitu jelas, sehingga kita harus memilih mana yang dianggap wujud dan sebaliknya mana yang dianggap sebagai latar.

b. Pola pengelompokan (teori Gestalt)

Secara sadar atau tidak sadar, kerap kali kita mengkelompokkan beberapa hal dalam persepsi kita. Pengelompokan tersebut menentukan bagaimana kita mengamati suatu hal. Dalam ilmu psikologi kecenderungan manusia untuk mengelompokkan persepi dinamakan hukum Gesalt. Termasuk di dalamnya adalah hukum kesamaan, hukum kedekatan dan hukum

c. Ketetapan (constancy atau invariance)

Teori gestalt juga mengemukakan bahwa dari proses belajar manusia cenderung mempersepsikan segala sesuatu sebagai sesuatu yang tidak berubah, walaupun indera kita menangkap adanya perubahan. Misalnya kita bertemu bernama seseorang bernama Peter, maka kita akan mengenal Peter walaupun dia menggunakan pakaian dan gaya yang berbeda setiap harinya. Dalam persepsi ada tiga ketetapan dasar yang dikemukakan dalam Psikologi Gesalt, yaitu Ketetapan Warna, Ketetapan Bentuk, dan Ketetapan Ukuran

\section{METODE PENELITIAN}

Penelitian ini menggunakan metode penelitian deskriptif-kualitatif. Artinya bahwa penelitian ini bukan berupa data yang bersifat numeris melainkan menggunakan prosedur penelitian yang menghasilkan data deskriptif berupa gambar, kata-kata, baik lisan maupun tulisan serta perilaku orang yang diamati yang dalam hal ini adalah user/pemain game. Kemudian data yang ada diproses dengan pendekatan kualitatif menggunakan teori Komunikasi dan teori Persepsi Visual seperti yang dijabarkan di atas. Selanjutnya data tersebut dianalisis dengan metode komparasi antara tampilan visual game Super Mario Bros versi 2 Dimensi (2D) dengan game Super Mario Bros versi 3 Dimensi (3D) untuk mendapatkan rumusan dasar pengembangan konsep visual game baik dalam versi 2D maupun 3D.

\section{DATA DAN ANALISA}

\subsection{Game Super Mario Bros}

Mengapa game Super Mario Bros?. Karena game ini salah satu game terbaik dengan memegang tujuh rekor Guiness dalam jumlah penjualan game terbanyak sepanjang waktu. Hal ini menunjukkan bagaimana game Super Mario disukai masyarakat. Dan parameter suka disini diawali kesukaan terhadap unsur visual pada game ini yaitu karakter dan aset lingkungan game yang simple tapi desain menarik serta mudah ditangkap penggambaran layout yang diberikan. Karakter Mario yang menjadi ikon Nitendo merupakan karakter terbaik sepanjang masa bersama dengan karakter lain seperti Sonic, Lara Craft, dan sebagainya versi London Game Festival. (http://www.andriewongso.com) 


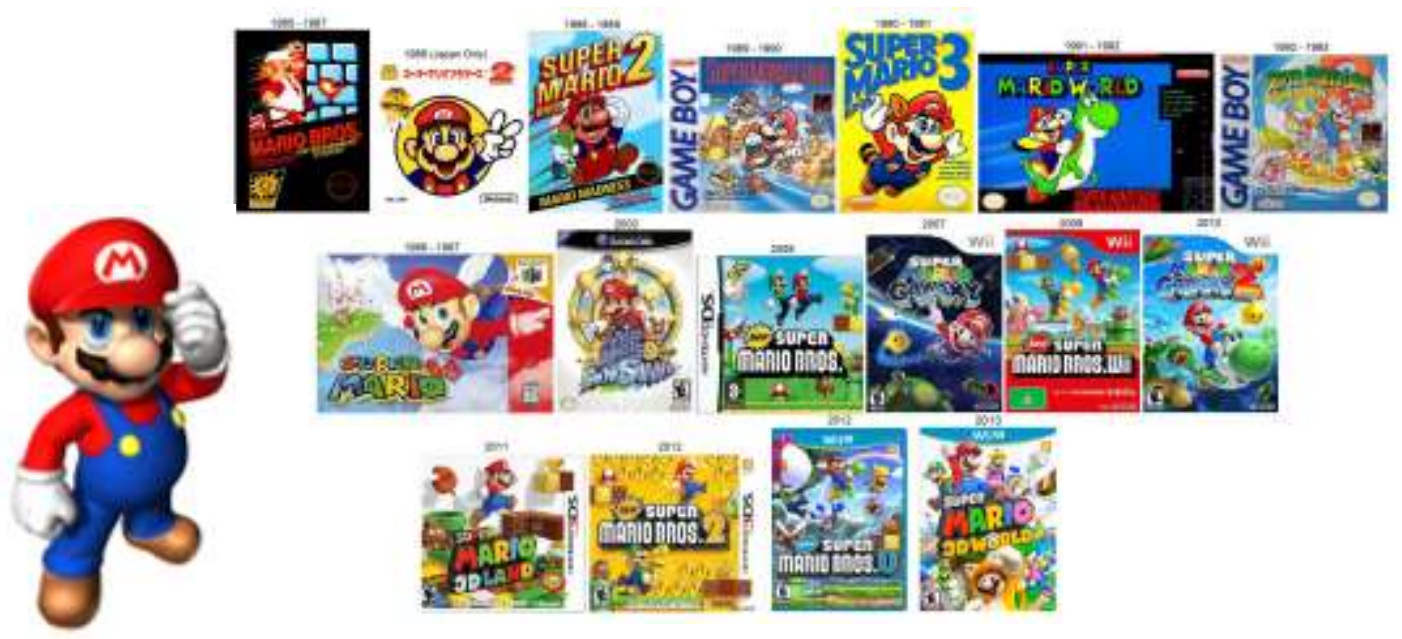

Gambar 2. Game Super Mario Bros dari masa ke masa (sumber:http://theodysseyonline.com/manhattan-college/)

Selain itu game Super Mario Bros dalam perkembangannya muncul dalam versi 2D game dan 3D game. Hal ini melengkapi kajian analisis pengembangan konsep visual game pada 2D dan 3D game dengan metode komparasi. Itulah mengapa game Super Mario Bros sangat layak untuk menjadi dasar pengembangan konsep visual game. Sehingga fokus penelitian ini akan melihat kecenderungan interaksi antara user dengan tampilan visual game dan bagaimana komunikasi dari interaksi ini terbentuk sehingga persepsi visual user dapat diarahkan dan pesan yang disampaikan oleh game diterima dengan baik oleh user dengan menganalisis tampilan visual pada game Super Mario Bros 2D dan 3D.

\subsection{Analisis Model Pengembangan Visual Game}

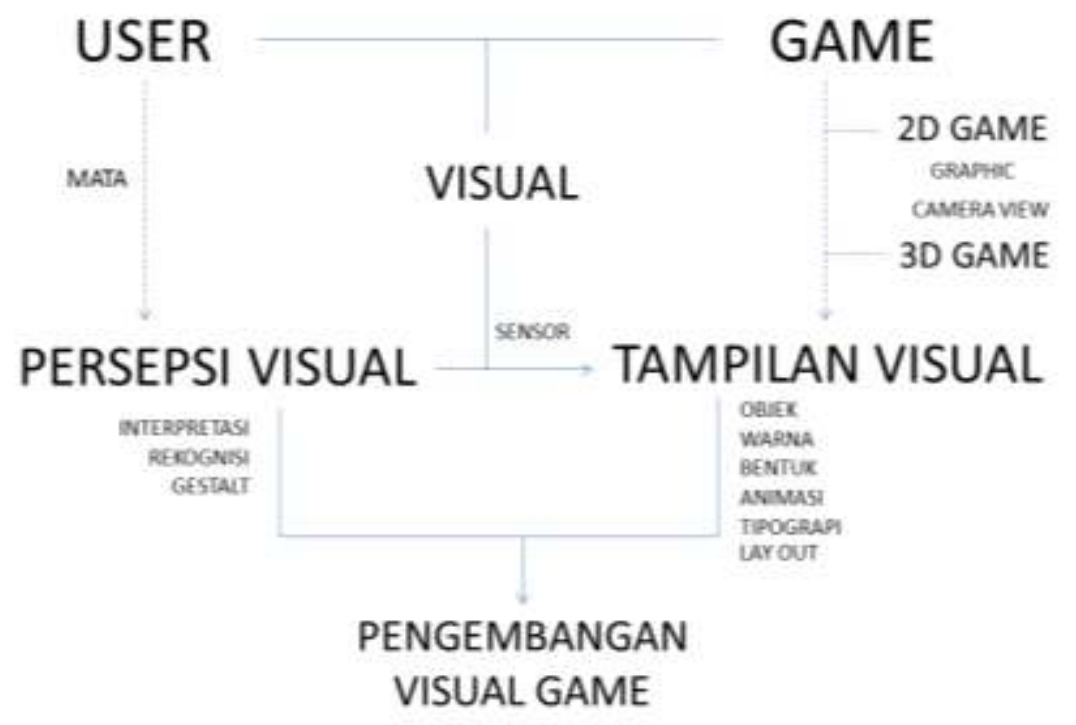

Gambar 3. Tahap Persepsi Visual User dalam Kaitannya dengan Pengembangan Visual Game 
Persepsi visual mengenai tampilan visual game yang meliputi objek, karakter, bentuk dan warna, animasi, dan desain layout, akan diinterpretasi oleh user melalui otaknya sebagai sebuah satu makna yang saling berkaitan yang memiliki satu kesatuan desain sebagai sebuah game. Tampilan visual yang baik akan menarik user untuk memberikan respon dengan mulai memainkan game tersebut. Kemudian saat user memainkan game, dia akan mulai menganalisis setiap elemen visual game untuk mengenali lingkungan game yang ditampilkan oleh si pembuat game. Maka di sinilah tugas pembuat game untuk membuat konsep visual game dengan elemen visual dan desain layout yang mudah dipahami oleh si user.

Kecenderungan user melihat setiap elemen visual sebagai sebuah kesatuan visual dalam wujud sebuah game memberikan perhatian lebih pada pengembangan konsep layout game, yaitu pengorganisasian keseluruhan elemen-elemen visual game yang ditata letaknya sedemikian rupa, agar user mampu menginterpretasikan desain tersebut sebagai sebuah desain yang enak dilihat dan memacu untuk berinteraksi dengannya. Sehingga user yang telah tertarik dengan tampilan visual game dan mulai memainkannya akan berupaya masuk lebih jauh, memainkan game hingga selesai. Dan akhirnya user akan merasa terbawa oleh permainan, merasa terhibur dan secara tak langsung menerima pesan yang tersirat dalam game tersebut.

\subsection{Analisis Game Super Mario Bross Dalam Kajian Persepsi Visual User}

Game Super Mario Bros dalam perkembangannya hadir dalam 2D game dan 3D game. Hal ini sebagai bukti eksistensi Super Mario Bros dalam menghadirkan game yang sesuai dengan perkembangan teknologi visual saat ini.

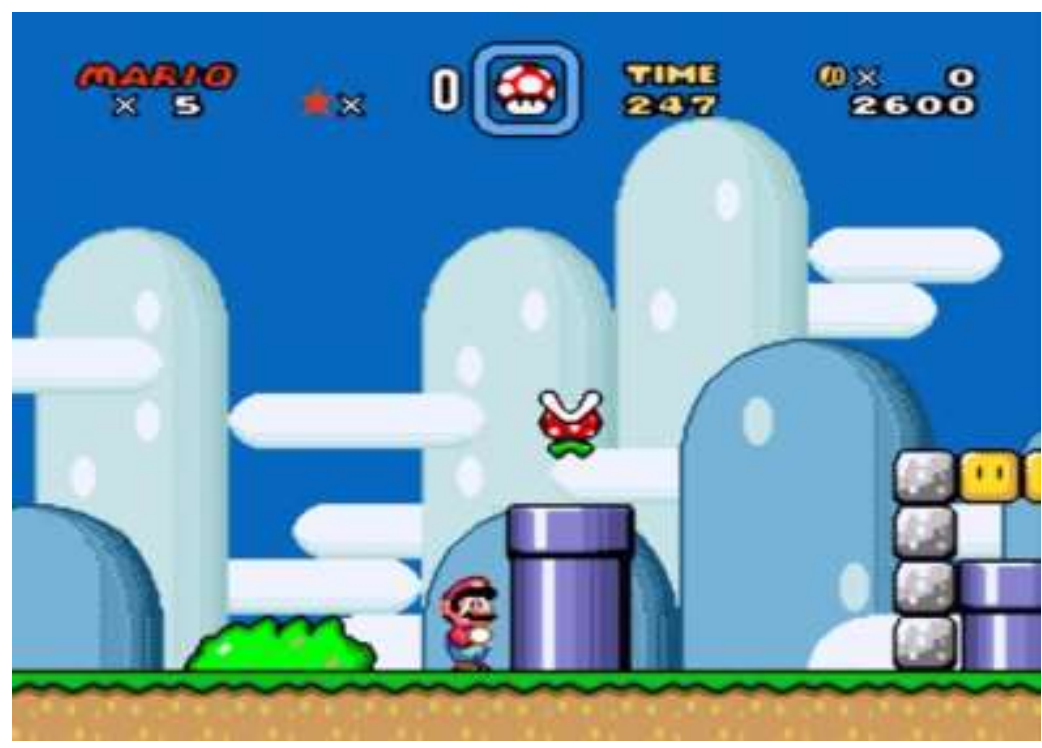

Gambar 4. Tampilan game Super Mario Bros 2D 


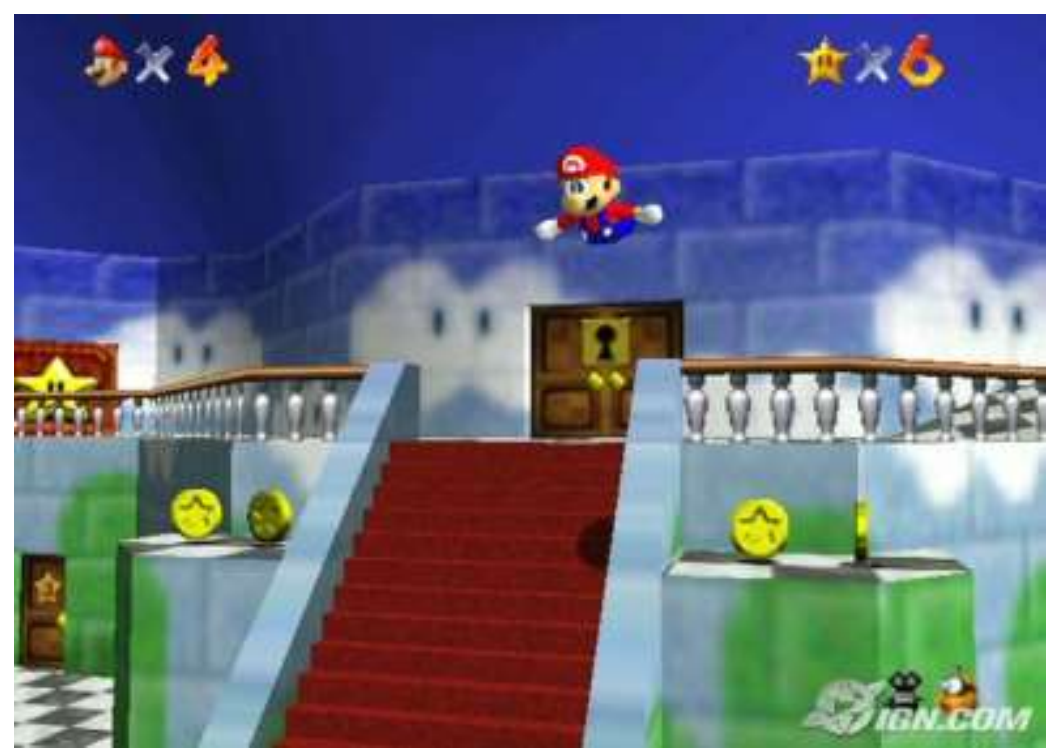

Gambar 5. Tampilan game Super Mario Bros 3D

Kedua genre game ini dapat dianalisis tampilan visualnya dengan metode komparasi sebagai dasar pengembangan game dan hasilnya adalah sebagai berikut:

Tabel 1. Karakteristik Umum Persepsi User Tentang Objek pada Tampilan Visual Game Super Mario Bros 2D dan 3D

\begin{tabular}{|c|c|c|}
\hline Parameter & Game Mario 2D & Game Mario 3D \\
\hline & $\begin{array}{l}\text { - Cenderung user melihat } \\
\text { objek sebagai unsur visual } \\
\text { yang bergerak kurang } \\
\text { dinamis }\end{array}$ & $\begin{array}{l}\text { O Cenderung user melihat objek } \\
\text { sebagai unsur visual yang } \\
\text { bergerak secara dinamis, lebih } \\
\text { nyata dan lebih interaktif }\end{array}$ \\
\hline & - Kekuatan ilustrasi gambar & o Kekuatan modelling objek \\
\hline Karakter & $\begin{array}{l}\text { - Kejelasan karakter meski } \\
\text { tidak harus detail }\end{array}$ & $\begin{array}{l}\text { O Detail Karakter dan gerak animasi, } \\
\text { bentuk proporsional }\end{array}$ \\
\hline Lingkungan & $\begin{array}{l}\text { - Bentuk dan warna jelas, } \\
\text { kontras dengan lingkungan }\end{array}$ & $\begin{array}{l}\text { O Pemberian warna yang } \\
\text { mempertimbangkan tingkat point } \\
\text { of interestnya }\end{array}$ \\
\hline
\end{tabular}

Pandangan user ketika melihat tampilan visual game berupa objek yaitu karakter dan aset environment/lingkungan mereka menekankan pada tampilan objek yang mudah dikenali mana karakter, mana lingkungannya. Sehingga konsep nirmana sangat menentukan tercapainya pesan tersebut yaitu tentang bagaimana kejelasan sebuah objek, detail, warna, kesatuannya dan bentuknya. 
Tabel 2. Karakteristik Umum Persepsi User Tentang View pada Tampilan Visual Game Super Mario Bros 2D dan 3D

\begin{tabular}{|c|c|c|}
\hline Parameter & Game Mario 2D & Game Mario 3D \\
\hline \multirow{4}{*}{$\begin{array}{l}\text { View } \\
\text { (Sudut } \\
\text { Pandang) }\end{array}$} & - Daya eksplorasi user terbatas & o Daya eksplorasi user tinggi \\
\hline & $\begin{array}{l}\text { - Identifikasi visual user lebih } \\
\text { cepat }\end{array}$ & $\begin{array}{l}\text { o Identifikasi visual user dengan } \\
\text { eksplorasi }\end{array}$ \\
\hline & $\begin{array}{l}\text { - Cenderung lebih fokus pada } \\
\text { satu objek visual yaitu } \\
\text { karakter }\end{array}$ & $\begin{array}{l}\text { o Cenderung fokus terbagi pada } \\
\text { beberapa objek visual }\end{array}$ \\
\hline & - Interpretasi lebih cepat & o Interpretasi lebih lama \\
\hline
\end{tabular}

View disini adalah tampilan yang diperlihatkan oleh kamera atau tampilan layar dalam game. Pada game 2D, view cenderung statis sehingga sering terlihat tampilan flat, dan kedalaman kurang, berbeda dengan tampilan 3D yang cenderung dinamis, penuh dengan kedalaman dan terlihat realistis. User memandang view sebagai daya eksplorasi persepsi mereka, tingkat fokus penglihatan mereka, dan tingkatan kecepatan mereka menginterpretasikan objek-objek visual. Pengenalan objek yang lebih cepat diinterpretasikan memungkinkan pesan lebih mudah dipahami oleh user.

Tabel 3. Karakteristik Umum Persepsi User Tentang Komposisi pada Tampilan Visual Game Super Mario Bros 2D dan 3D

\begin{tabular}{|c|c|c|}
\hline Parameter & Game Mario 2D & Game Mario 3D \\
\hline \multirow{3}{*}{ Komposisi } & $\begin{array}{l}\text { - Penggunaan teknik komposisi } \\
\text { Bagian depan dan latar } \\
\text { belakang Yaitu fokus pada } \\
\text { area permainan bukan pada } \\
\text { latar belakang game }\end{array}$ & $\begin{array}{l}\text { Penggunaan teknik komposisi } \\
\text { Aturan segitiga pada fokus } \\
\text { utama game yaitu karakter, } \\
\text { sehingga elemen visual game } \\
\text { lebih mudah diinterpretasi }\end{array}$ \\
\hline & $\begin{array}{l}\text { - Elemen yang kecil, kontras } \\
\text { tinggi, mempunyai pengaruh } \\
\text { sama dengan elemen yang } \\
\text { besar dan tidak tajam }\end{array}$ & $\begin{array}{l}\text { O Setiap elemen game saling } \\
\text { mendukung dalam upaya } \\
\text { memperlihatkan pusat perhatian } \\
\text { pada karakter. }\end{array}$ \\
\hline & $\begin{array}{l}\text { Warna latar lebih gelap atau } \\
\text { terang dan pemberian ruang } \\
\text { kosong pada latar }\end{array}$ & $\begin{array}{l}\text { o Pencahayaan yang baik dan } \\
\text { bayangan memudahkan } \\
\text { identifikasi unsur visual }\end{array}$ \\
\hline
\end{tabular}


Komposisi dalam peletakan objek-objek visual serta teknik pengambilan kamera mempengaruhi tingkat kemudahan user menginterpretasikan objek. Objek yang dinamis seperti karakter akan dikenali oleh user pertama kali, sehingga sangat penting pengaturan komposisi yang mengedepankan objek sebagai pusat perhatian.

Tabel 4. Karakteristik Umum Persepsi User Tentang Desain Layout pada Tampilan Visual Game Super Mario Bros 2D dan 3D

\begin{tabular}{|c|c|c|}
\hline Parameter & Game Mario 2D & Game Mario 3D \\
\hline \multirow{6}{*}{ Layout } & $\begin{array}{l}\text { - Cenderung melihat setiap } \\
\text { unsur visual game sebagai satu } \\
\text { kesatuan }\end{array}$ & $\begin{array}{l}\text { o Cenderung melihat setiap unsur } \\
\text { visual game sebagai satu bagian } \\
\text { yang memiliki interaksi }\end{array}$ \\
\hline & $\begin{array}{l}\text { - Cenderung melihat unsur } \\
\text { visual yang memiliki } \\
\text { kedekatan, kesamaan, dan } \\
\text { alur }\end{array}$ & $\begin{array}{l}\text { o Cenderung melihat unsur visual } \\
\text { dengan analisis kesamaan dan } \\
\text { ketertutupan }\end{array}$ \\
\hline & - Letak objek visual diatur layer & $\begin{array}{l}\text { o Letak objek visual diatur } \\
\text { koordinat }\end{array}$ \\
\hline & $\begin{array}{l}\text { - Objek yang memiliki kesamaan } \\
\text { diletakkan berdekatan disusun } \\
\text { secara berurutan sebagai latar }\end{array}$ & $\begin{array}{l}\text { o Penempatan objek diatur dengan } \\
\text { kemudahan identifikasi visualnya } \\
\text { dengan pencahayaan yang baik }\end{array}$ \\
\hline & $\begin{array}{l}\text { - Objek bagian depan berupa } \\
\text { karakter dan objek lingkungan } \\
\text { yang jarak penempatan diatur } \\
\text { tidak sama }\end{array}$ & $\begin{array}{l}\text { o Karakter sebagai fokus diletakkan } \\
\text { sesuai teknik komposisi sehingga } \\
\text { area layar terlihat seimbang }\end{array}$ \\
\hline & $\begin{array}{l}\text { - Informasi nyawa, poin, score } \\
\text { bisa diletakkan di tepi atas } \\
\text { /bawah }\end{array}$ & $\begin{array}{l}\text { O Informasi nyawa, poin, score bisa } \\
\text { diletakkan di tepi atas/bawah }\end{array}$ \\
\hline
\end{tabular}

Desain tata letak memberikan informasi secara keseluruhan pada layar permainan. Darley (1986) melihat kecenderungan pengorganisasian tata letak secara keseluruhan ada pada prinsip-prinsip gestalt tentang pengelompokan (gestalt priciples of grouping) yang berpijak pada kecenderungan manusia untuk mengorganisasi stimuli yang terpisah menjadi pengelompokan yang berdasar pada proximity (kedekatan), similarity (kemiripan), closure (ketertutupan), continuity (kesinambungan), dan symmetry (simetris). Pada tampilan visual game prinsip kesatuan, kesamaan, jarak, dan alur sangat berpengaruh besar di sini. User memandang desain layout yang mampu menyatukan beberapa kriteria bentuk objek yang berbeda, memiliki kesamaan, 
terdapat jarak dan alur sebagai desain yang lebih mudah dipahami oleh user. Tidak membingungkan, dan pesan akan sampai pada user.

Selain memberikan gambaran bagaimana persepsi user dalam melihat pola-pola hubungan dalam sebuah tampilan visual game, penelitian ini juga menemukan pengaruh persepsi visual game terhadap user yaitu:

1. User memiliki fokus yang lebih terhadap apa yang terjadi di sekelilingnya

2. Peningkatan dalam visual skill.

3. Meningkatkan kemampuan otak kanan untuk memecahkan masalah yang membutuhkan pengenalan pola, mendeteksi kecenderungan-kecenderungan, membuat hubungan-hubungan, dan mengetahui keseluruhan hal.

\section{KESIMPULAN}

Dari uraian masalah tentang peran game sebagai media komunikasi visual dan kajian persepsi visual user yang berperan dalam pengembangan game yang menarik dan menghibur serta mampu menyampaikan pesan kepada user itu sendiri, dapat disimpulkan bahwa sebuah game membutuhkan interaksi yang aktif dari user untuk memainkannya, di mana dalam interaksi tersebut muncul komunikasi secara visual dalam upaya menyampaikan pesan melalui media game. Layaknya komunikasi verbal antar individu, komunikasi visual antara user dengan game ini juga membutuhkan tingkat perhatian yang lebih dan fokus dari user sebagai penerima pesan. Tingkat perhatian ini ditunjukkan oleh bagaimana user memaknai simbol atau tanda-tanda visual yang ada dalam game sebagai sebuah kesatuan yang dapat dimainkan dari beberapa elemen visual game seperti, karakter, bentuk dan warna, animasi, dan desain layout.

Dan untuk menciptakan tingkat perhatian yang diinginkan agar pesan dapat sampai ke user, pembuat game harus mampu mengembangkan konsep visual game dengan mempelajari persepsi visual user dalam memandang sebuah tampilan visual dengan menghubungkannya pada prinsip mendesain dan prinsip pembuatan game. Game versi 2D memiliki karakteristik yang berbeda dengan game versi 3D baik dalam tampilan visual maupun dampak yang dihasilkan kepada user. Karakteristik masingmasing game telah disebutkan dalam pembahasan sebelumnya. Sedangkan dampak yang psikologi yang dihasilkan sebuah tampilan game terhadap user yaitu game 2D memberi dampak kepada user untuk terbiasa fokus pada suatu masalah dengan melihat pola penyederhanaan suatu fenomena tertentu. Sedangkan game 3D memberi dampak kepada user untuk terbiasa fokus pada suatu kondisi tertentu dalam suatu frame masalah dengan identifikasi pada suatu pola hubungan tertentu. 


\section{DAFTAR PUSTAKA}

Aprilia, Shieny dan Widhiyasa, Arief. Membuat Game dengan XNA Game Studio. Bandung: Agate.

Mulyana, Deddy. 2005. Ilmu Komunikasi Sebuah Pengantar. Bandung: PT Remaja Rosdakarya.

Lasswell, Harold D. 1972. The structure and function of communication in society dalam Wilbur Schramm, ed. Mass communication. Chicago: University of Illinois Press.

Darley, John M. 1986. Psychology, 3rd edition. New Jersey: Prentice-Hall.

Sarwono, Sarlito W. 2012. Pengantar Psikologi Umum. Jakarta: Rajawali Pers

Walgito, Bimo. 2004. Pengantar Psikologi Umum. Yogyakarta: Penerbit Andi

Internet:

http://www.andriewongso.com/articles/details/5141/Inilah-3-Game-Klasik-SepanjangMasa 
Andharupa, Jurnal Desain Komunikasi Visual \& Multimedia. Vol.01 No.02 Tahun 2015 